\title{
Successful endoscopic management of Bouvaret syndrome using laser lithotripsy
}

A 64-year-old white woman, with a remote history of cervical cancer, for which she underwent hysterectomy, and diverticulosis with a colovaginal fistula in the distal sigmoid colon, presented with passage of a grape-sized stone per vagina. On chemical analysis, this was identified as being a cholesterol gallstone, which prompted further investigations.

A computed tomography (CT) scan showed a fistulous communication between the gallbladder and the colon, as well as a cholecystoenteric fistula

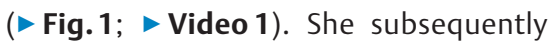
presented with symptoms suggestive of gastric outlet obstruction. Upper gastrointestinal endoscopy and endoscopic ultrasound (EUS) showed a 5-cm hard stone partially impacted in the pyloric channel, compatible with a diagnosis of Bouvaret syndrome ( $\boldsymbol{F}$ Fig. 2 a). A cholecystoduodenal fistula was seen in the duodenal bulb, with a pigment stone impacted at the fistulous opening. Attempts to remove the stone by mechanical means, including net, snare, extraction balloon, talon, and electrohydraulic lithotripsy for fragmentation, were unsuccessful. Laser lithotripsy (0.3 J energy at $50 \mathrm{~Hz}$ ) ( Fig. 2 b) was successful in partial pulverization ( $\boldsymbol{F}$ Fig. $\mathbf{2 c}$ ) and all fragments were then extracted ( $\triangleright$ Video 1 ). The gastroscope was then advanced beyond the cholecystoduodenal fistula ( $\vee$ Fig. 2 d) into the second portion of the duodenum, demonstrating clearance of the gastric outlet obstruction.

After 3 weeks, a repeat CT scan showed a decompressed gallbladder with spontaneous passage of all stones, and cholecystectomy was therefore deferred. She underwent a hand-assisted laparoscopic sigmoid resection with splenic flexure mobilization, and her post-operative recovery has been uneventful in the 5 months since surgery.

Bouvaret syndrome describes gastric outlet obstruction from an impacted gallstone in the duodenum after its passage through a cholecystoduodenal fis-
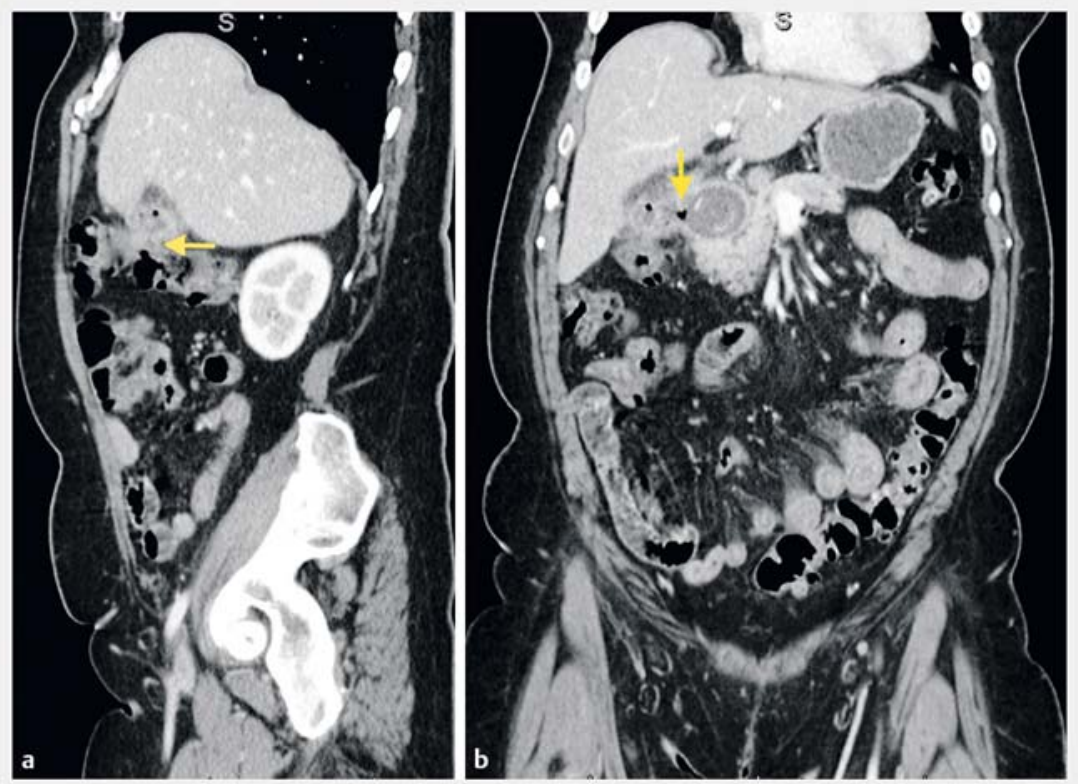

- Fig. 1 Computed tomography scan showing: a a fistulous communication between the gallbladder and the colon; $\mathbf{b}$ a cholecystoenteric fistula.
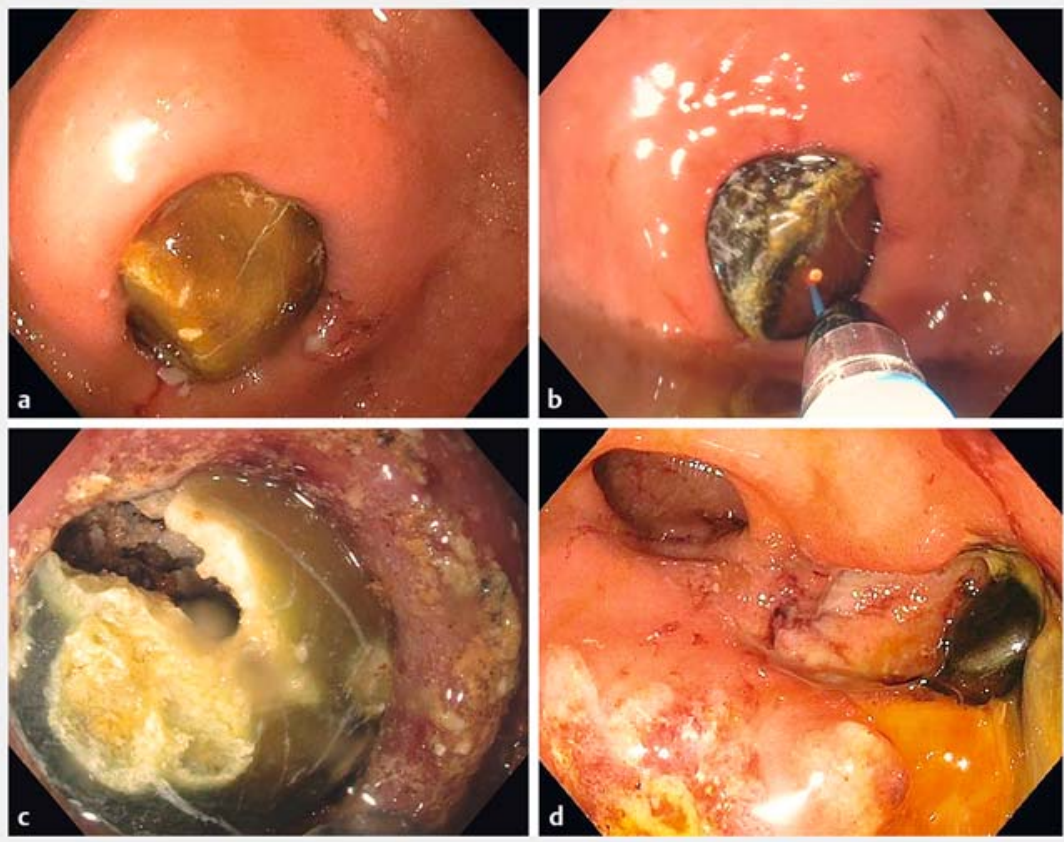

- Fig. 2 Endoscopic views showing: a a gallstone impacting in the pylorus; $\mathbf{b}$ laser lithotripsy being applied to the gallstone; $c$ partial fragmentation of the gallstone using laser lithotripsy; d the cholecystoduodenal fistula after clearance of the gastric outlet obstruction. 


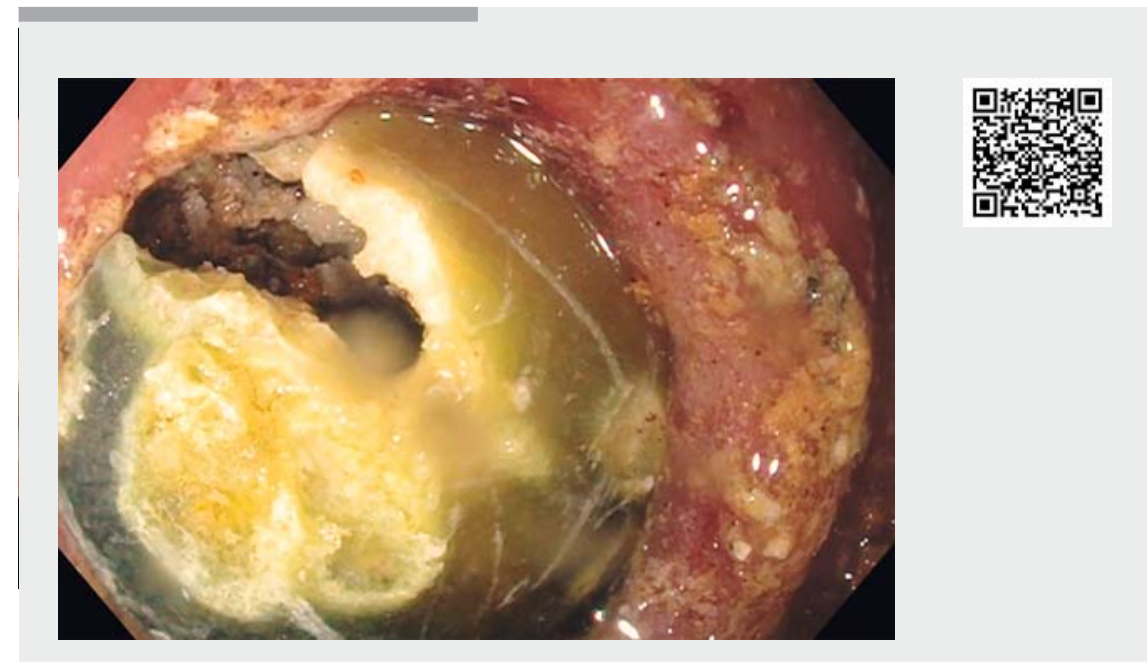

Video 1 Computed tomography views of the fistulous communications; endoscopic views of the impacted gallstone, unsuccessful attempts to remove it, and application of laser lithotripsy with partial fragmentation; view of the cholecystoduodenal fistula after clearance of the gastric outlet obstruction.

tula [1]. Our case presents an unusual journey of a migrating stone fragment, first through a cholecystoduodenal fistula into the colon, then through a colovaginal fistula, which was followed ultimately by per-vaginal passage. We also report the successful use of laser lithotripsy for precise targeting of energy onto a stone with minimal tissue injury. This offers a less invasive and low risk therapeutic alternative to surgery [2]. This video was previously awarded the ACG presidential poster award and presented at American College of Gastroenterology, 2018, Philadelphia.

Endoscopy_UCTN_Code_CPL_1AK_2AF

\section{Competing interests}

Martin Freeman has consultancy agreements with Boston Scientific and AbbVie.

The authors

Guru Trikudanathan', Dupinder Singh', Kyle Anderson ${ }^{2}$, Eric Jensen ${ }^{3}$, Robert Madoff ${ }^{4}$,

\section{Martin L. Freeman ${ }^{1}$}

1 Division of Gastroenterology, Hepatology and Nutrition, University of Minnesota, Minneapolis, Minnesota USA

2 Department of Urology, University of Minnesota, Minnesota, USA

3 Division of Surgical Oncology, University of Minnesota, Minneapolis, Minnesota, USA

4 Division of Colo-rectal surgery, University of Minnesota, Minneapolis, Minnesota, USA
Corresponding author

\section{Guru Trikudanathan, MD}

Division of Gastroenterology, Hepatology and Nutrition, University of Minnesota, MMC 36, 420 Delaware St SE, Minneapolis, MN 55455, USA

Fax: +1-612-625-5620

triku001@umn.edu

\section{References}

[1] Cappell MS, Davis M. Characterization of Bouveret's syndrome: a comprehensive review of 128 cases. Am J Gastroenterol 2006; 101: 2139-2146

[2] Duenas CS, Fernandez-Urien I, Iriarte MR et al. Laser lithotripsy resolution for Bouveret syndrome. Endoscopy 2017; 49 (Suppl. 01): E101-E102

\section{Bibliography}

DOI https://doi.org/10.1055/a-0915-1603

Published online: 23.5.2019

Endoscopy 2019; 51: E305-E306

(C) Georg Thieme Verlag KG

Stuttgart · New York

ISSN 0013-726X

\section{ENDOSCOPY E-VIDEOS \\ https://eref.thieme.de/e-videos}

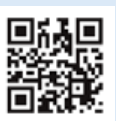

Endoscopy E-Videos is a free access online section, reporting on interesting cases and new

techniques in gastroenterological endoscopy. All papers include a high quality video and all contributions are freely accessible online.

This section has its own submission website at https://mc.manuscriptcentral.com/e-videos 